\title{
FEASIBILITY STUDY: \\ PASS COMPUTER ENVIRONMENT
}

American Management Systems, Inc.

\author{
Prepared For: \\ U.S. DEPARTMEIT OF ENERGY \\ Assistant SECRETARY FOR ENVIRONMENT \\ OFFICE OF TECHNOLOGY IMPACTS \\ Policy Analysis Division \\ MARCH 10, 1980
}

Under Contract IJumber: DE-ACO2-79EV10274 


\section{DISCLAIMER}

This report was prepared as an account of work sponsored by an agency of the United States Government. Neither the United States Government nor any agency Thereof, nor any of their employees, makes any warranty, express or implied, or assumes any legal liability or responsibility for the accuracy, completeness, or usefulness of any information, apparatus, product, or process disclosed, or represents that its use would not infringe privately owned rights. Reference herein to any specific commercial product, process, or service by trade name, trademark, manufacturer, or otherwise does not necessarily constitute or imply its endorsement, recommendation, or favoring by the United States Government or any agency thereof. The views and opinions of authors expressed herein do not necessarily state or reflect those of the United States Government or any agency thereof. 


\section{DISCLAIMER}

Portions of this document may be illegible in electronic image products. Images are produced from the best available original document. 


\section{Feasibility Study: \\ PASS Computer Environment}

American Management Systems, Inc.

Prepared for:

U.S. DEPARTMENT OF ENERGY

Assistant Secretary for Environment

Office of Technology Impacts

Policy Analyșis Division

March 10,1980

Under Cuntract Number: DE-ACO2-79EV10274

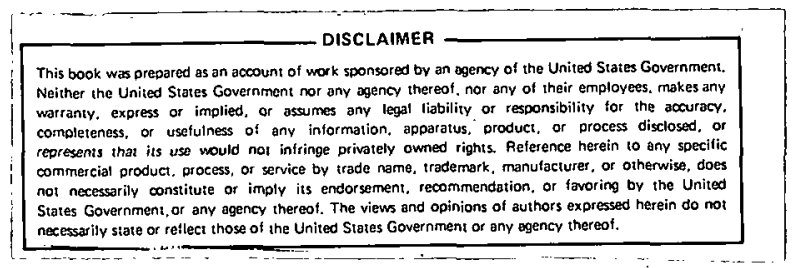




\section{EXECUTIVE SUMMARY}

The Policy Analysis Screening System (PASS) is a computerized informationretrieval system designed. to provide analysts in the Department of Energy, Assistant Secretary for Environment, Office of Technology Impacts (DOE-ASEV-OTI) with automated access to articles, computer simulation outputs, energy-environmental statistics, and graphics. Although it is essential that PASS respond quickly to user queries, problems at the computer facility where it was originally installed seriously slowed PASS's operations. Users attempting to access the computer by telephone repeatedly encountered busy signals and, once logged on, experienced unsatisfactory delays in response to commands. Many of the problems stemmed from the system's facility manager having brought another large user onto the system shortly after PASS was implemented, thereby significantly oversubscribing the facility. Although in March 1.980 Energy Information Administration (EIA) transferred, operations to its own computer facility, OTI has expressed concern that any improvement in computer access time and response time may not be sufficient or permanent. Consequently, a study was undertaken to assess the current status of the system, to identify alternative computer environments, and to evaluate the feasibility of each alternative in terms of its cost and its ability to alleviate current problems.

Alternatives Considered and Evaluation Criteria

This study considered three alternatives for PASS's hardware: (1). stay with EIA and use the new facility; (2) move PASS to another mainframe computer at an outside service bureau; and (3) convert PASS to a Sykes Comm-Stor IV microcomputer.1/ In evaluating these alternatives, the following operational criteria were stressed:

- The system should be able to process queries quickly from a large data base of about 5000 articles.

- Analysts at remote locations should be able to query the data base directly without either having to go through a PASS operator or having to follow complex procedures.

- The system should be able to store and retrieve graphics and tables from DOE models already in PASS.

I/ To expand its processing capabilities, OTI has ordered three Sykes Comm-Stor IV units which would be used if PASS were converted to a dedicated computer. 
Costs were also a major consideration. Any additional development, operation, or maintenance costs associated with leaving the EIA facility should be clearly outweighed by gains in performance in the above areas.

Conclusion

Based on our evaluation, we believe that remaining with EIA is the most desirable option for PASS. Some of the chief reasons are:

- By moving to an entirely new computer system, EIA appears to have taken a major step towards improving service to its users. The new system has significantly more CPU capability, disk storage, and ports for incoming telephone 1 ines. The system also has ports available for hardwired terminals to Forrestal OTI offices, where most PASS users are now located. If OTI chooses to instali hard-wired terminals, it will have added assurance of good response time, since computer access time will effectively be reduced to zero.

- As indicated, disk storage space should present no problem àt EIA, but any storage option currently available with the Sykes would severely degrade system response time.

- Staying with EIA requires no modification to current PASS software, whereas using either a service bureau or the Sykes would necessitate major re-design and re-programming, additional user training, and documentation revision. In operation and maintenance, the Sykes would be doubly expensive and cumbersome, since a version of PASS would have to be kept on the mainframe to perform certain functions.

Concern about PASS's computer environment was generated by intolerable conditions at EIA. These conditions, which did not appear until about one month after PASS was implemented, were ascribed to the addition of one large customer (not PASS) to the system. Before that, system response was adequate. By moving to the new computer, EIA should improve service, and we expect that EIA will continue trying to solve future problems. By choosing to hardwire terminals to its Forrestal Offices, OTI can gain added assurance that conditions will remain good for the majority of PASS users. In addition to offering a responsive hardwire environment, staying with EIA is also the least expensive and least disruptive alternative. Moreover, the opportunity exists to move to another computer environment later, should EIA performance not meet expectations. If OTI chose to install PASS on a microcomputer or service bureau at this time and EIA service did not degrade, considerable time and resources would have been wasted. 


\section{Feasibility Study: PASS Computer Environment}

\section{Introduction}

The Policy Analysis Screening System (PASS) is a computerized information-retrieval system designed to provide analysts in the Department of Energy, Assistant Secretary of Environment, Office of Technology Impacts (DOE-ASEV-OTI) with automated access to articles, computer simulation outputs, energy-environmental statistics, and graphics. Each article-in PASS has been assigned a set of keywords that describe the source, scope, and subject matter of the article. Articles. relating to specified topics are accessed by making a "query," that is, by putting together a string of keywords. PASS then locates a11 articles on topics represented by the keywords.

A.though it is essential that PASS respond quickly to user queries, problems at the computer facility where it was originally installed seriously slowed PASS's operations. Consequently, a study was undertaken to assess the current status of the system, to identify alternative computer environments, and to evaluate the feasibility of each alternative in terms of its ability to alleviate current problems and its cost. The remainder of this paper presents the results of that study.

II. Current System Status

This section describes the current hardware environment of PASS as well as specific problems experienced with that environment. 


\section{A. Overview of Current System}

PASS was originally implemented on an IBM $370 / 168$ at Optimum Systems, Inc. (OSI) which contracted with the Enerav Information Administration (EIA) to provide computer services. More recentiy, EIA transferred operations to its own IBM 3033 computer facility in the Forrestal Building. Most of PASS is programmed in SUPERWYLBUR MACRO language, although graphics are displayed using the Computer Generated Graphics System (CGGS) package in IBM's TimeSharing Option: (TSO).

There are currently 1400 articles on the PASS Articles Data Base, with this number expected to increase significantly, possibly to 5000 articles by the end of 1981. After its initial expansion, continuous maintenance should keep the size of the data base constant at approximately 5000 articles. With roughly 1.2 articles per track, 30 tracks per cylinder, 555 cylinders per IBM 3350 diskpack, the Articles Data Base alone will fill over, one-third of one diskpack. This estimate does not include storage space for the PASS programs, other data files, and index, which require an additional 10 cylinders.

\section{B. Problems Experienced}

Shortly after PASS was implemented on the IBM 370/168, OSI brought another large user onto the same computer, significantly oversubscribing its capacity. During peak hours, users attempting to access the computer by telephone repeatedly encountered busy signals. Once logged on, users experienced slow response to on-line commands, sometimes waiting several minutes for response to individual commands. Character transmission was frequently garbled, which further delayed response time. Analysts attempting direct queries of the data base expressed frustration over the slow response, and some were discourgaged from further attempts. In March 1980, EIA transferred 
operations to its own computer facility, the IBM 3033 in the Forrestal Building. Although the change is expected to provide improvement in computer access and response time, OTI has expressed concern that the improvement may not be sufficient or long-lasting.

To assess the significance of this problem, it is necessary to understand how analysts will. use PASS. Partly because of the computer problems and partly because the data base contains a 1 imited number of articles, PASS has received few queries from OTI analysts. Assuming that these deficiencies are remedied, OTI analysts estimate that they will use PASS from three to five times per week. With 20 analysts using PASS, the system will process approximately 80 queries per week. An analyst must be able to process a query personally or to have a PASS operator available for processing the request. If an operator processes a query, printed output should be on the user's desk within 24 hours; output from an analyst's direct query should be available within two hours. Response time during PASS sessions must. be quick enough to avoid user frustration. While a terminal must be accessible to all analysts, user query frequency does not demand a large number of terminals. A few strategically-placed terminals in Germantown, Forrestal, and contractor offices should be sufficient. In addition, users should be able to dial up from other remote locations.

Interviews with OTI analysts indicate a need for an efficient, quick, text-retrieval system. Although PASS software is complete, a shortage of articles and poor computer access and response time have contributed to the system's lack of use. An effort is underway to expand and update the data base. But without good computer access and response time, PASS will be no more effective than manual research methods. Thus, to make PASS more usable, al ternatives that could improve PASS's computer environment must be considered. The remaining sections of this paper evaluate three major alternatives identified as potential solutions by OTI. 


\section{Alternative Solutions}

There are several potential solutions to the problems that have plagued PASS's computer environment. One alternative is to stay with EIA and utilize the new facility in Forrestal. Although OTI has expressed some doubts about remaining with EIA, the potential expense and administrative difficulties associated with leaving EIA require that this alternative be examined. A second alternative is to move. PASS to another mainframe computer. Since policies on use of existing DOE computers appear to limit an energy information system like PASS to EIA's facility, PASS would need to be moved to a computer at an outside service bureau. A third alternative is to purchase or lease a minicomputer or microcomputer that would be dedicated to PASS. OTI has ordered three Sykes Comm-Stor IV units which would be used if PASS were converted to a dedicated computer. 1 / Thus, the focus of this paper will be on these al ternatives:

- Remain with EIA;

- Move PASS to a service bureau's mainframe computer; or

- Convert PASS to a Sykes Comm-Stor IV microcomputer.

In evaluating each alternative, several questions must be answered:

- How well would the computer environment enable PASS to meet the stated system requirements (acceptable access time, reasonable response time, storage capacity for 5000 articles plus programs, remote dial-up capability, graphics capability, quick turnaround for printed output)?

- What are the dollar and time costs to make PASS operational?

II As we understand it, the Sykes units will be needed for other functions besides PASS. 
- What are the dollar and time costs in operating and maintaining PASS?

- What kind of changes would be required to current PASS procedures?

- What can be expected from the computer environment in the future?

The answers to these questions will serve as points of comparison among the three alternatives. In the next sections, each alternative will be described and evaluated.

\section{A. $\underline{E I A}$}

One option for PASS is to remain with EIA. Although EIA has experienced severe computer problems, the situation has improved significantly with the recent switch to the new facility in the Forrestal Building. The new system consists of two IBM 3033 computers operating in multi-processing mode with 24 channels. The new system features:

- Main memory of eight megabytes (roughty 1.5 times that of the old system);

- 80 IBM 3350 diskpacks (old system had 53);

- 176 300-baud ports for incoming telephone lines (old system had 145);

- Four circuits available for hard-wired clusters of 32 terminals; 
- Same versions of SUPERWYLBUR and TSO;

- Technical support provided by. Electronic Data Systems (EDS).

The increased CPU capability will translate to roughly $50 \%$ improvement in response time if the number of users remains the same. Since EIA users are no longer competing with a service bureau's other users, EIA may initially see even greater improvement. Ninety-six of the 300-baud ports can also support 1200-baud support terminals; more 1200-baud terminals used means quicker terminal sessions and, consequently, better response:-for other users. Another feature of the new system is that, unlike the system at OSI, the equipment can be expanded. More rotary modems to support 300/1200-baud terminals and more circuits for hard-wired terminals can be added, should the need arise.

At least for the near future, staying with EIA is an attractive al ternative. The EIA system offers the following advantages:

- No incremental hardware or software costs: PASS software is operational on the new system and no special additional equipment must be purchased.

- OTI can use EIA's facilities free of charge.

- Computer access is adequate. The number of incoming i.ines on the new system is sufficient to enable users to call in at all hours of the day without encountering busy signals.

- Disk storage is also adequate and response time is usually fast. Occasionally, the system hesitates in its response to on-line commands, but disk access is no longer frequently queued, as was the case at the OSI facility. 
- Printed output is easily routed from the computer at Forrestal to analysts's desks.

By and large, the changeover appears to have been handled painlessly. All operations on the old system appear to work on the new one. Occasional system hesitation may be a result of initial conversion problems, but could result in inconvenience if persistent. Another possible problem is the new system's handling of batch jobs; the new system gives higher priority to on- 1 ine and postpones major batch processing till off-hours. PASS applications requiring batch processing are thus somewhat delayed.

Nevertheless, while the near future at EIA looks promising, long-term conditions are less predictable. If the responsiveness of the new EIA computer is to remain acceptable, the number of users allowed access to the system must be carefuliy monitored. Unfortunately, EIA does not control the number of users; the individual offices and divisions within DOE do. Without centralized control of customer allocation, the number of users can again grow to be too many for the system to handle. Consequently, the system may, once again, become oversubscribed.

Recognizing that the future performance of EIA is uncertain, two strategies can minimize negative impacts of long-range computer problems:

- Use a dedicated diskpack;

- Use terminals that are hard-wired into 'EIA's computer.

A dedicated diskpack is reserved for a specific set of users, such as PASS users: A11 PASS programs and the Articles Data Base could easily fit onto one IBM 3350 diskpack. Since the computer would no longer need to search a catalog to locate files, response time during the user session would improve slightly. A dedicated diskpack would not, however, solve problems 
of user inability to access the computer. To obtain a dedicated diskpack, OTI would have to submit an Energy Data Services Request (EDSR) and provide detailed justification of needs. EDSR approval is not automatic and may take several weeks or more.

A second strategy involves having terminals hard-wired directly into EIA's computer through a high-speed port. Using hard-wired terminals would el iminate the need to dial the computer, since the terminals would always be ready for use. Thus, computer access time would never be a problem. In addition, hard-wiring results in faster response time during user sessions because there are no line delays. One limitation is that hard-wired terminals must be installed in the same building as the computer. Conveniently, both the computer and PASS's principal user, the Policy Analysis Division, are located in the Forrestal Building. Users at Germantown and at contractor offices would continue to dial up, however.

Applications for hard-wired terminals must be approved by the Energy Data Service at the Office of Automated Data Processing (ADP). The initial paperwork takes about one month to be processed. Although approval is not automatic, the implication from people at ADP was that a valid request would be fulfilled. After approval, it takes another month for ADP to coordinate installation. The physical location of the terminals determines the difficulty of installation. If one room is reserved for all the terminals, coaxial cables can be routed from that room to the computer facility. Installing cables becomes more complicated, however, if terminals are situated in each of several offices. The Facilities Management Office as well as ADP would need to approve such a set-up. Since one purpose of PASS is to bring computerized searching power closer to analysts, it mav be necessarv to install terminals in clerical areas of each suite of offices at Forrestal, despite the extra complexity and paperwork. 
If a decision is made to hard-wire terminals, thought must be given to the type of terminal installed. Installation and maintenance are easier if the terminals are IBM 3270 s or equivalent, but 3270 s do not support graphics. Although graphics terminals can physically be hard-wired, ADP does not ordinarily do so since such terminals usually require high-speed ports. ADP would probably not allow PASS's graphics terminals to be hard-wired. Retrieval of graphics articles would, therefore, still have to be accomplished by dialing up.

Finally, staying at EIA preserves flexibility.: Now that EIA's new system is operational, PASS.' $\hat{\mathrm{S}}$ computer environment should improve without requiring any changes to PASS or expenditures by OTI. To ensure that system responsiveness remains good, hard-wired terminals can be acquired at no cost and installed without interrupting PASS operations. If the computer situation worsens in spite of these measures, alternatives can still be evaluated and adopted at a later date.

\section{B. Service Bureau}

A second option is to buy time and space on a mainframe at an outside service bureau. Under such a contract, PASS data and programs would be converted to the service bureau's computer environment.

A request for outside time-sharing must be submitted to the DOE Office of Computer Services and Telecommunications Management (CSTM), Division of Technical Support. The Telecommunications Service Program at the General Services Administration (GSA) requires CSTM to evaluate the request with respect to 45-50 established vendors in order to determine the most competitive rates. 
The following facts pertain to the cost evaluation:

- Users are charged on the basis of CPU time, connect time, I/O, materials, and storage space used. A system like PASS would cost, roughly, $\$ 1,500$ per month;

- Dedicated disks are readily available at a fixed cost (about $\$ 1,400$ per month). If most of the space is utilized, using dedicated disks is cheaper than using shared disks:

- Technical support is provided free of charge unless an extraordinary amount is required.

Preparing the request and the subsequent evaluation takes roughiy three months. CSTM will deny the request if it cannot justify the cost of going outside DOE for computer services.

Because service bureaus differ, nothing definite can be stated about the future computer environment for PASS under this alternative. It is assumed that CSTM would select the least costly service bureau with sufficient memory and storage capacity to handle PASS. With respect to computer access and response time, nothing can be assured except that an outside vendor has a business interest in pleasing its clients, and, thus might tend to monitor the number of users. There would be no constraints on the location of terminals, although they must be compatible with the computer at the service bureau. Printed output could be delivered by courier from the service bureau or routed to a remote station at DOE. 
An important consideration in assessing the service bureau option is the fact that SUPERWYLBUR is a proprietary product to which only OSI and the Federal government have rights. Consequently, SUPERWYLBUR is not available at any service bureau. When PASS was originally designed in August 1979, the features and capabilities of SUPERWYLBUR were a major factor in making design decisions. Therefore, a switch to another programming language would necessitate re-designing and re-programming PASS. This effort, which would include testing, user training, and documenting, would likely take at least five man-months, or about $\$ 35,000$. Exhibit 1 outlines the tasks that would be involved in this effort.

\section{Microcomputer}

A third option is to acquire a smal1, dedicated computer. A variety of minicomputers and microcomputers are on the market, each with its own main memory, storage capacity, and other features. Since OTI has expressed interest in a Sykes Comm-Stor IV microcomputer, the following analysis will consider PASS specifically in relation to the Sykes. Among the features of the Sykes are:

- Main memory of $40 \mathrm{~K}$ bytes:

- Single or dual floppy disk (256k"bytes) drives;

- Programmable in BASIC;

- Three ports (for terminat, modem, and printer) with speed of 50-9600 baud;

- No competition with other users for computer time;

- Technical support office in Falls Church, Virginia. 


\section{EXHIBIT 1}

Tasks to Convert PASS to Service Bureau

Tasks

Evaluate computer language options available

Design classification scheme

Develop detailed design specifications

Write and test programs

Perform overall system tests

Develop conversion specifications

Implement conversion

Provide system documentation

Train users and operators
No. of Hours Dollars $0 \$ 36$ Per Hour

40

$\$ 1,440$

40

1,440

180

6,480

400

14,400

100

3,600

40

1,440

40

1,440

100

3,600

40

980
1,440

$\$ 35,280$ 
The Sykes Comm-Stor IV is not a multi-user operating system; that is, each Sykes unit can support only one user at a time. Consequently, at least three sets of microcomputer hardware would need to be acquired, one each for Germantown, Forrestal, and the contractor's offices. Each would have identical hardware and software configurations consisting of the basic unit, modem, terminal, and printer. Each basic unit can be leased for approximately $\$ 200$ per month. OTI can either ask CSTM to place the order, or place it itself. In either case, it takes less than a week for the order to be filled.

If only floppy disks are used, storage capacities on the Sykes limit the system's responsiveness. With a dual drive system, two 256K floppy disks can be loaded at one time. Presently, the PASS index alone requires over $320 \mathrm{~K}$ bytes of storage space and is expected to grow. With $40 \mathrm{~K}$ bytes of main memory, the Sykes could handle. less than one-eighth of the current index at one time. Thus, each query through the: index would require.nine swaps through ma in memory, adversely affecting response time. Since the Articles Data Base occupies about 96 megabytes, it would require as many as 375 256K-byte disks. In the course of a query, a user would have to change disks many times.

There are several potential solutions to the storage capacity problems created by floppy disks. One"alternative, hard disks, would provide faster data access than floppy disks and storage capacities of 5-10 megabytes, thereby aliminating many of the above concerns. System software for hard disks has not, however, yet been developed for the Sykes. Although an outside party could develop this software, specifically for PASS, the time and dollar expense involved makes this approach impractical. I/

\footnotetext{
1/ Normally, hardware vendors develop such enhancements in the course of improving their products, thereby spreading the development costs lover all potential customers.
} 
A second storage alternative is to use the diskpacks on a mainframe as the storage device; however, reading articles from the mainframe to the microcomputer over regular telephone lines, which transmit only 37.5 characters per second, is extremely slow.

A third alternative, magnetic tape cartridges, would store 2.5 megabytes per cartridge. Presently the Articles Data Base fills about 96 megabytes; thus about 39 cartridges would be required to provide enough space. Users would have to switch tapes frequently during PASS sessions. Since tapes do not provide the random access available with hard disks, their use with PASS would degrade response time, although less so than floppy disks. Moreover, as with hard disks, system software for magnetic tape cartridges has not yet been proven successful for the Sykes.

The computer environment offered by the Sykes has other drawbacks. Without on-site technical support, DOE analysts would be forced to do most technical debugging and systems operations themselves. This is critical, since most users are not accustomed to performing maintenance tasks such as making backups and loading disks. The situation becomes even more critical when users are confronted with hardware problems that they are unable to diagnose or solve. Consequently, although computer access time is no problem when the system is operable, insufficient technical support would translate to more time that the system is not available. As mentioned earlier, response time would be adequate only if a solution were found for the storage capacity problems. 
Floor space requirments are also a consideration with the microcomputer. About four square feet must be available in each prospective terminal location to house all the necessary equipment. One advantage of the Sykes is that, with a printer located near each terminal, all printed output would be immediately available. Another advantage is that graphics could be prepared on a mainframe and recorded on a Sykes floppy disk for immediate playback at any time.

The Sykes cannot perform certain functions necessary for maintaining PASS and for meeting stated systems requirments.: For this reason, a fully-operational version of PASS would need to be maintained on a mainframe. Functions that the mainframe would perform are:

- Receiving incoming calls from remote locations;

- Allowing an interface to computer simulation outputs and other special data bases;

- Reading tapes produced by OCR and word-processing to convert them to whatever form of storage is used;

- Producing graphics displays.

It is conceivable that systems software could be developed that would allow the Sykes to assume some of these tasks, but there is no, guarantee this will be available in the near future.

Another consideration is that a major re-design and re-programming effort wouid be necessary to convert PASS into BASIC. This imposes the same disadvantage of the service bureau approach. Using floppy disks for storage, 
the costs of conversion would be around $\$ 35,000$, as outlined in Exhibit 2 . Having both a microcomputer version and a mainframe version of PASS doubles the program and data maintenance tasks and requires that two sets of documentation be kept up to date.

Perhaps the chief advantage of acquiring a dedicated small computer like the Sykes is that is would give OTI tight control over PASS's computer environment. The number of users competing for terminal time could be based strictly on OTI's priorities. The limitations discussed above, however are likely to offset these gains. Moreover, expense: of conversion would be significant, assuming that the mainframe continues to perform the functions defined earlier. Software to enable the sykes to assume all mainframe functions or expand its storage with hard disks or magnetic tape cartridges would involve additional expense.

IV. Conclusion

Three alternativesfor solving PASS's computer problem have been examined. Exhibit 3 characterizes each alternative with respect to the questions that were raised in Section III. Following are highlights of the differences among alternatives:

- The EIA option entails no monthly costs; the sykes would cost $\$ 200$ per month for each basic unit (total of $\$ 600$ for three units); the service bureau fee depends on the vendor selected, but would likely cost between $\$ 2000$ and $\$ 3000$ per month;

- Storage space presents no problem at EIA or a service bureau, but any storage option currently available with the Sykes would severely degrade response time; 


\section{EXHIBIT 2}

Tasks to Convert PASS to Microcomputer

$\underline{\text { Tasks }}$

Evaluate computer language options available

Design classification scheme

Develop detailed design specifications

Write and test programs

Perform overall system tests

Develop conversion specifications

Implement conversion

Provide system documentation

Train users and operators
No. of Hours Dollars \& $\$ 36$ Per Hour

40

$\$ 1,440$

40

1,440

180

6,480

400

$\therefore \quad 14,400$

100

3,600

40

1,440

40

1,440

100

3,600

40

980
1,440

$\$ 35,280$

I/ Cost would be much greater if no suitable graphics package were found. 


\begin{tabular}{|c|c|c|c|}
\hline System Requirements: & $\dot{E I A}$ & Service Bureau. & Sykes \\
\hline Access Time & $\begin{array}{l}\text { Would be no problem with hard- } \\
\text { wired terminals; adequate } \\
\text { without. }\end{array}$ & $\begin{array}{l}\text { Bureau would be selected that } \\
\text { would assure good access. }\end{array}$ & $\begin{array}{l}\text { Instantaneous, but can } \\
\text { only handle one user at } \\
\text { a time. }\end{array}$ \\
\hline Response Time & $\begin{array}{l}\text { New computer will upgrade re- } \\
\text { sponse; hard-wiring make it } \\
\text { even better. }\end{array}$ & $\begin{array}{l}\text { Bureau would be selected that } \\
\text { would assure good response. }\end{array}$ & $\begin{array}{l}\text { Inadequate until storage } \\
\text { problems are solved. }\end{array}$ \\
\hline Storage Space & $\begin{array}{l}\text { On } 3350^{\prime} s \text {, more than suffi- } \\
\text { cient. }\end{array}$ & $\begin{array}{l}\text { Bureau would be selected that } \\
\text { would assure sufficient stor- } \\
\text { age. }\end{array}$ & $\begin{array}{l}\text { On floppy disks } \\
\text { or tape cartridges. }\end{array}$ \\
\hline Dial-up Capability & Yes. & Yes. & No. \\
\hline Graphics Capability & Yes. & $\begin{array}{l}\text { Bureau that provides CGGS } \\
\text { would be selected. }\end{array}$ & $\begin{array}{l}\text { Would record output } \\
\text { from CGGS for immediate } \\
\text { playback. }\end{array}$ \\
\hline Printed Output & $\begin{array}{l}\text { Within stated time require- } \\
\text { ments. }\end{array}$ & $\begin{array}{l}\text { Within stated time require- } \\
\text { ments. }\end{array}$ & $\begin{array}{l}\text { Within stated time re- } \\
\text { quirements. }\end{array}$ \\
\hline $\begin{array}{l}\text { Start-up Costs: } \\
\$\end{array}$ & None. & $\$ 35,000$ & $\$ 35,000$ \\
\hline Time & None. & $\begin{array}{l}3 \text { months paper work; } 5 \text { man- } \\
\text { months for design and imple- } \\
\text { mentation. }\end{array}$ & $\begin{array}{l}5 \text { man-months for design } \\
\text { and implementation. }\end{array}$ \\
\hline$\$$ itenance Costs: & None. & $\$ 2500 /$ month & $\begin{array}{l}\$ 600 / \text { month, not includ- } \\
\text { ing cost of technical } \\
\text { support. }\end{array}$ \\
\hline Time & None. & None. & $\begin{array}{l}\text { Must provide own tech- } \\
\text { nical support. }\end{array}$ \\
\hline Changes to PASS & None. & $\begin{array}{l}\text { Re-design, re-programming, } \\
\text { new documentation. }\end{array}$ & $\begin{array}{l}\text { Re-design, reprogramm- } \\
\text { ing, new documentation. }\end{array}$ \\
\hline Future & $\begin{array}{c}\text { Looks very good if hard-wired; } \\
\text { promising wi thout.: } \\
\text { : }\end{array}$ & Probably good." & $\begin{array}{l}\text { Unpredictable; depends } \\
\text { on development of sys- } \\
\text { tems software and } \\
\text { available technical } \\
\text { suppurl. }\end{array}$ \\
\hline
\end{tabular}

\section{EXHIBIT 3}

COMPARISON OF ALTERNATIVE

HAROWARE ENVIRONMENTS 
- The EIA option requires no modification to the current PASS software; using either a service bureau or the Sykes would force major re-design and re-programming;

- PASS is presently operational at EIA; a microcomputer version could be operable after an estimated five man-months of design and implementation; because of DOE standard procedures, PASS could be converted to a service bureau environment in, at best, three calendar months;

- Technical support would be good at EIA or a service bureau, but may be a problem with the Sykes.

Concern about PASS's computer environment was generated by the intolerable conditions arising at EIA, shortiy after PASS was implemented. PASS users were not the only people, however, affected by the oversubscription; all EIA users have suffered. By moving to an entirely new computer system, EIA has taken a major step toward improving computer conditions for its users. Whille no assurances can be given, there is every reason to expect that EIA will continue trying to improve its computer services in the future. The associated option of hard-wiring terminals offers faster access and response time. In addition to the prospect of a desirable computer environment, staying with EIA is also the least expensive, least disruptive, and most flexible alternative. Therefore, when all points are considered, remaining at EIA is the most desirable option for PASS. 
ams

\section{AMERICAN \\ MANAGEMENT \\ SYSTEMS, INC.}

\section{Corporate and}

Eastern Offices

1515 Wilson Boulevard

Arlington, Virginia 22209

(703) 841-6000

Waçhington, D.C. Office

734 15th Street, N.W.

Washington, D.C. 20005

(703) 841-5858

New York Regional Office

90 Williant Street

New York, New York 10038

(212) 269-2700

Boston Office

One Washington Mall

Boston, Massachusetts 02108 (617) 367-3155

Midwestern Regional Office

120 South Riverside Plaza

Chicago, Illinois 60606

(312) 648-5555

Detroit Office

3001 West Big Beaver Road

Troy, Michigan 48084

(313) 643-4900

Western Regional Office

561 Pilgrim Drive

San Mateo, California 94404

(415) 573-9481

San Diego Office

11610 Iberia Place

San Diego, California 92128

(714) 743-7681

Computer and

Micromation Centers

1901 North Moore Street

Arlington, Virginia 22209

(703) $841-6200$ 